\title{
Clinical Presentations, Diagnosis and Pattern of Intestinal Tuberculosis, Our Experience, Nishtar Hospital Multan, Pakistan
}

M AZIZ N JAMAL M I FARID $M A Z I Z$

Department of Accident \& Emergency, Nishtar Hospital, Multan

Correspondence to Dr: Muzaffar.Aziz.Senior Registrar 0300-6334203,drmuzaffaraziz@yahoo.com

Objective: To discuss clinical presentations, diagnosis and pattern of intestinal tuberculosis of the patients presenting in surgical department. Design. Retrospective study. Place and duration of study. Nishtar Hospital Multan, Pakistan during the period of January 2002 to August 2004. Patients and methods. 109 diagnosed cases of intestinal tuberculosis were included in this study. Patients with intercurrent illness and patients proved to have other diagnosis after full work up were excluded from the study. A detailed history and full physical examination of all patients was recorded. Later on various investigations, operative findings were also noted. Results. The ages of patients were in range of $12-54$ years. Male to female ratio was approximately 1:2. Clinical presentation was quite variable ranging from abdominal pain present in 100 patients $(91.74 \%)$ to weight loss noted in 54 patients $(49.54 \%)$. Endoscopic biopsy and PCR analysis were most useful in diagnosing intestinal tuberculosis in elective cases. Strictures of the small bowel were commonest pattern noted. Past history of pulmonary tuberculosis was present in 8 patients $(7.33 \%)$ while 18 patients $(16.51 \%)$ had previous history of intestinal tuberculosis. 35 patients $(32.11 \%)$ had positive family history of tuberculosis. $18.34 \%$ of the patients had secondary tuberculosis. Conclusion. Intestinal tuberculosis is a common disease in third decade in the developing countries. Females are more affected than males. Primary tuberculosis is more common than secondary tuberculosis. Intestinal tuberculosis may present with a variety of abdominal symptoms and signs. Endoscopy and PCR analysis can be considered as reliable investigation in elective cases. Strictures, mass abdomen and intestinal perforation are the most common pattern observed.

Key words. Abdominal Pain, Weight loss, PCR (polymerase chain reaction), endoscopy

Tuberculosis is the one of commonest chronic inflammatory disease of small bowel '. The ileocaecal region is the commonest site in the bowel and the lesion may spread to the ascending colon. As elsewhere in the body, tuberculosis in the alimentary tract forms granulomas. These may be evident clinically and radiologically as an ulcer, a mass or a hypertrophic tumor (tuberculoma) in shronic infection or if the patients immunity is sufficient there is fibrosis, leading to stricture or a malfunction of normal alimentary peristalsis ${ }^{2}$.

Abdominal tuberculosis had continued to be recognized as common health problem in Indian subcontinent and many African countries and despite improvement in the methods of hygiene and advances in prophylaxis and drug therapy, it remained the major cause of morbidity and mortality ${ }^{3}$. Although it has become now a rare problem in the western countries as a result of eradication of tuberculous herds and introduction of pasteurized milk, effective chemotherapy for primary tuberculosis and generalized improvement in living condition and nutrition ${ }^{4}$. Intestinal tuberculosis may be of two varieties;

1. Primary tuberculosis caused by ingestion of milk containing mycobacterium bovis. It is caused by ingestion of un-pasteurized milk.

2. Secondary tuberculosis caused by mycobacterium tuberculosis is due to swallowing of infected sputum.

Tuberculosis is neither rare nor confined only to the poor but also affects malnourished and debilitated patients ${ }^{5}$. The diagnosis is not difficult in societies where the disease is common and clinicians are aware of it. Abdominal tuberculosis is usually of insidious onset with diverse symptoms and signs. A few patients present with complication of perforation, obstruction or bleeding ${ }^{6}$. If clinical suspicion of abdominal tuberculosis is high a trial medical treatment is appropriate. Surgery should be reserved for complications of disease ${ }^{7}$.

The purpose of study is to know different clinical presentations of intestinal tuberculosis of the patients presenting in surgical department.

\section{Material and methods:}

Study design: This retrospective study including 109 patients of intestinal tuberculosis was conducted in surgical unit IV at Nishtar Hospital Multan, Pakistan from January 2001 to August 2004.

Inclusion criteria: All diagnosed cases of intestinal tuberculosis were included in this study.

\section{Exclusion criteria:}

1. Patients with intercurrent illness.

2. Patients proved to have other diagnosis after full work up.

A detailed history including socioeconomic status of patients and full physical examination was conducted. Later on various clinical presentations of patients, various investigations and operative findings were discussed. Acute intestinal obstruction was considered if patients had pain abdomen, absolute constipation, vomiting and abdominal distention for 24-48 hours with radiological findings of supporting the clinical observation. 
Subacute intestinal was accepted if patient had relative constipation, vomiting, pain abdomen and abdominal distention for more than 48 hours with radiological findings supporting the clinical observation. Peritonitis accepted if the patient had abdominal symptoms with marked localized or generalized guarding or rigidity and tenderness.

As this is a descriptive study so only percentages and ratios are calculated for data analysis by SSPS system.

\section{Results:}

This study included 109 patients. 95(87.15\%) patients were admitted though emergency ward and 14 (12.84\%) patients were admitted through out patients department. The ages of patients were in range of $12-54$ years (table 1 ). Most of them were in their third decade. There were 38 males $(34.86 \%)$ and $71(65.13 \%)$ females. Male to female ratio was approximately $1: 2$. All the females were malnourished and 70 females had multiple pregnancies having more then 7 kids. Six females were infertile due to tuberculous of the female genital organs.

Table 1: Age \& sex of patients $\left(n^{\prime}=109\right)$

\begin{tabular}{lllll}
\hline Age range & Male & Female & Total & \%age \\
\hline $12-20$ & 5 & 16 & 21 & 19.26 \\
$21-35$ & 7 & 32 & 39 & 35.77 \\
$36-45$ & 13 & 15 & 28 & 25.68 \\
$46-54$ & 8 & 13 & 21 & 19.26 \\
Total & 33 & 76 & 109 & \\
\hline
\end{tabular}

All the patients belonged to low socioeconomic group. Most of the patients were living a life of below the line of poverty. 90 patients $(82.56 \%)$ belonged to rural areas where proper housing facilities were not available. There was no concept of ventilation and hygiene in their lives. 19 patients $(17.43 \%)$ were living in urban areas but having similar problems of housing as mentioned above. 39 patients $(35.77 \%)$ were laborers and remaining 70 patients $(64.22 \%)$ were farmers. Their yearly income was not more than 30000 to 40000 Pak rupees (265.48 to 353.98 Pound Sterling). 95 patients $(87.15 \%)$ were un-educated while remaining patients were educated up-to matriculation levels.

In the present study $20(18.34 \%)$ patients presented with peritonitis, $56(51.37 \%)$ patients presented with acute intestinal obstruction and 33(30.27\%) patients presented with signs and symptoms of sub-acute intestinal obstruction. Abdominal pain was commonest presenting complaint and present in 100 patients (91.74\%). Abdominal pain was associated with nausea and vomiting in 60 patients $(55.04 \%)$. Constipation was present in 75 patients $(68.80 \%)$. Diarrhea was noted in 10 patients $(9.17 \%)$. Fever was present in 74 patients $(67.88 \%)$. Weight loss was noted in 54 patients $(49.54 \%) .15$ patients (13.76\%) complained of malena. Past history of pulmonary tuberculosis was present in 8 patients $(7.33 \%)$ while 18 patients $(16.51 \%)$ had previous history of intestinal tuberculosis. 35 patients $(32.11 \%)$ had positive family history of tuberculosis. 20 patients (18.34) \% had secondary tuberculosis while 89 patient's $(81.65 \%)$ had primary tuberculosis.

Cervical lymph nodes were palpable in 28 patients $(25.68 \%)$. On abdominal examination, distention was noted in 71 patients $(65.13 \%)$, abdominal tenderness in 50 patients $(45.87 \%)$ and abdominal mass was present in 13 patients $(11.92 \%) .87$ patients $(79.81 \%)$ were anemic i.e. haemoglobin $<10 \mathrm{gm} / \mathrm{dl}$. White blood cell count was raised in 40 patients $(36.69 \%)$ i.e. total leukocyte count was more than $11000 / \mathrm{mm}^{2}$. In 52 patients $(47.70 \%)$ lymphocytes were more than $50 \%$. ESR was raised (ESR $>30 \mathrm{~mm}$ in first hour) in 70 patients $(64.22 \%)$. Tuberculin test was done in 45 patients $(41.28 \%)$, it was positive in 32 patients $(68.88 \%$ ) (table 2).

Table 2: Investigations performed ( $\mathrm{n}=109)$

\begin{tabular}{llll}
\hline Investigation & $\begin{array}{l}\text { No. of } \\
\text { Patients }\end{array}$ & $\begin{array}{l}\text { No. of +ve } \\
\text { cases }\end{array}$ & \%age \\
\hline Hb & 109 & 87 & 79.81 \\
TLC & 109 & 40 & 36.69 \\
ESR & 109 & 70 & 64.22 \\
Lymphocyte count & 109 & 52 & 47.70 \\
Tuberculin Test & 45 & 32 & 68.88 \\
Chest X-Ray & 109 & 20 & 18.34 \\
Barium Study & 29 & 22 & 75.86 \\
Abdominal Ultrasound & 109 & 47 & 43.11 \\
Ascitic fluid analysis by & 25 & 25 & 100 \\
PCR & & & \\
Colonoscopy & & & \\
- Biopsy & 15 & 15 & 100 \\
- PCR analysis & 15 & 14 & 93.33 \\
Biopsy & 109 & 109 & 100 \\
\hline
\end{tabular}

X-ray chest was mandatory in all cases to see concomitant tuberculous lesions in the lungs and relieving signs consistent with tuberculosis was present in only 20 patients $(18.34 \%)$. Plain abdominal $\mathrm{x}$-ray, in erect posture was done in all cases. 52 patients $(47.70 \%)$ showed distended bowel loops with air fluid levels and air under diaphragm was present in 14 patients $(12.84 \%)$.

Ultrasonography was performed in all patients. In 25 patients $(22.96 \%)$, there was ascities with thickened bowel loops in 22 patients (20.18\%). Ascities was aspirated and PCR was performed on the fluid positive in all $25(100 \%)$ patients. Mass was present in right lower abdomen in 15 patients $(13.76 \%)$. As malena was chief complaint in these 15 patients from relatively younger age group, so Colonoscopy and biopsy was performed to rule out Inflammatory Bowel Disease and malignancy. Colonoscopy (showing ulcerative lesion in the ileoceacal region) and biopsy specimen was further analyzed by PCR technique showing positive report for tuberculosis in 14 patients $(93.33 \%)$ while histopathology report was positive in $15(100 \%)$ patients. 
CT scan abdomen was also performed in these 15 patients having mass abdomen but it was not helpful in diagnosing tuberculosis.

Barium study was done in 29 patients. Only 20 patients showed narrowing and mucosal deformity in ileum ceacum and ascending colon and two patients showed multiple fistulae between small and large bowel that was confirmed on exploratory laparotomy. In 7 patients, no abnormality was detected.

All the patients underwent laparotomy (table 3 ). In 60 patients $(55.04 \%)$ had strictures in the gut, 18 patients (16.51\%) had intestinal perforation, 16 patients $(14.67 \%)$ had abdominal mass (table4) and 15 patients (13.76\%) had adhesions between the gut and abdominal wall. All patients received anti tubercolous therapy (Refampacin, Isoniazid, Ethumbutal and PZA) according to weight of patient. Resected tissues (affected bowel and lymph nodes) were sent for histopathology. Histopathology showed epitheliod granuloma with caseation necrosis and in most cases langerhan's giant cells.

Regarding follow-up, 49 patients (44.95\%) never came for follow-up. Out of remaining 60 patients (55.04\%), 5 patients developed jaundice. They were referred to medical unit for change in anti tubercolous therapy. Remaining 55 patients completed anti tubercolous therapy without complications.

Table 3: Operative finding

\begin{tabular}{|c|c|c|c|c|c|c|c|c|}
\hline Findings & Patients & \%age & Findings & Patients & \%age & Findings & Patients & \%age \\
\hline \multirow{5}{*}{$\begin{array}{ll}\text { Stricture } \\
\text { 1. } & \text { Single stricture } \\
\text { - } & \text { Stricture } 2 \text { feet } \\
& \text { from ileocaecal } \\
& \text { region } \\
\text { - Stricture } 1 \text { foot } \\
\text { from ileocaecal } \\
\text { region }\end{array}$} & 60 & 55.04 & Intestinal perforation & 18 & 16.51 & Mass & 16 & 14.67 \\
\hline & 32 & 55.1 & 1. Single & 12 & 80 & \multirow{4}{*}{ Ileum } & \multirow[t]{4}{*}{2} & \multirow[t]{4}{*}{13.3} \\
\hline & & & \multirow{3}{*}{$\begin{array}{ll}\text { - } & \text { Proximal ileum } \\
\text { - } & \text { Distil ileum } \\
\text { - } & \text { Ileocaecal area }\end{array}$} & 8 & 66.6 & & & \\
\hline & 18 & 56.2 & & & & & & \\
\hline & 14 & 43.7 & & 2 & 16.6 & & & \\
\hline 2. Multiple strictures & 26 & 44.8 & \multirow{3}{*}{$\begin{array}{ll}\text { 2. } & \text { Multiple } \\
& \text { Perforations } \\
\text { - } & \text { Proximal ileum } \\
\text { - } & \text { Distil ileum }\end{array}$} & 3 & 20 & \multirow[t]{4}{*}{ Ileocaecal } & \multirow[t]{3}{*}{6} & \multirow[t]{3}{*}{40} \\
\hline $\begin{array}{ll}\text { - } & \text { Stnctures in } \\
\text { proximal ileum } \\
\text { - } \\
\text { Strictures in distal } \\
\text { ileum }\end{array}$ & 15 & 57.6 & & 2 & 66.6 & & & \\
\hline \multirow[t]{2}{*}{$\begin{array}{l}\text { Strictures in } \\
\text { proximal and distil } \\
\text { ileum }\end{array}$} & 9 & 34.6 & & 1 & 33.3 & & & \\
\hline & 2 & 7.6 & & & & & & \\
\hline \multirow[t]{2}{*}{ Stricture with mass } & 6 & 10.3 & $\begin{array}{l}\text { Perforation } \\
\text { strictures }\end{array}$ & 5 & 33.3 & Region Caecal & 5 & 33.3 \\
\hline & & & & & & $\begin{array}{l}\text { Ileum, Ceacum } \\
\& \text { colon }\end{array}$ & 2 & 13.3 \\
\hline
\end{tabular}

Table 4: Comparison of mode of presentation

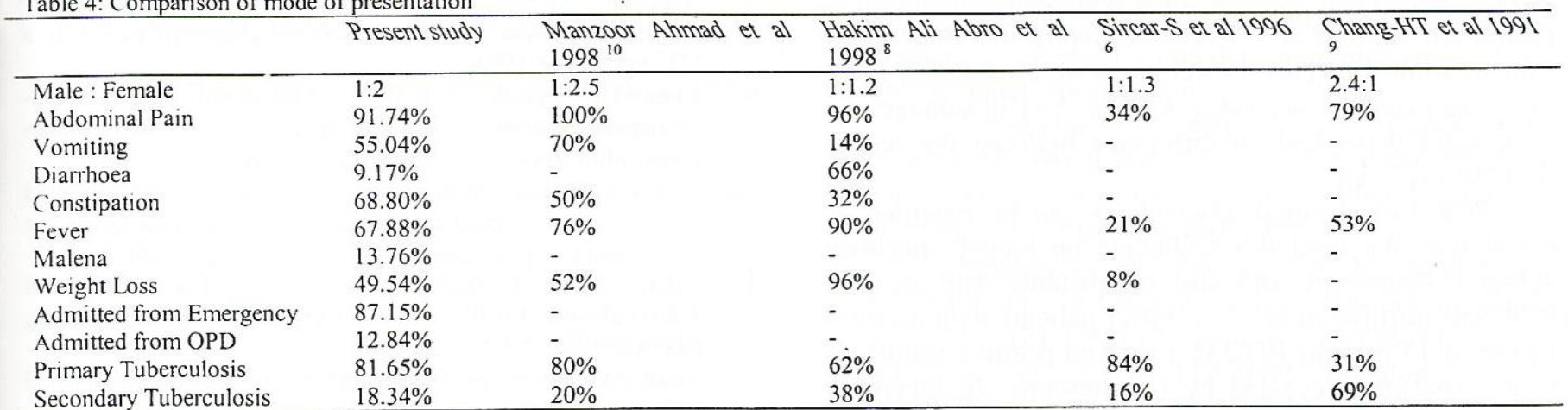

\section{Discussion:}

In the present study male to female ration was $1: 2$. Comparing to literature ${ }^{8}$ male to female ration was $1: 1.2$. In another literature male to female ratio was $2.4: 1^{9}$. In the developing countries like Pakistan, there is a male dominant society and females are particularly sufferers so tuberculosis is more common in these areas. Evidence of secondary tuberculosis was found in $18.34 \%$ patients in present study. In literature evidence of secondary tuberculosis was present in $16-20 \%{ }^{10,6}$.
Abdominal pain was commonest presenting complaint and present in 100 patients $(91.74 \%)$. Abdominal pain was associated with nausea and vomiting in 60 patients $(55.04 \%)$. Constipation was present in 75 patients $(68.80 \%)$. Diarrhea was noted in 10 patients $(9.17 \%)$. Fever was present in 74 patients $(67.88 \%)$. Weight loss was noted in 54 patients $(49.54 \%)$. Malena was chief complaint in 15 patients (13.76\%). Comparison of present study with other studies shown in (table4). Although there is significant difference between the results of present study and studies conducted by Sircar-S et $\mathrm{al}^{6}$ 
(1996) and Chang-HT et $\mathrm{al}^{9}$ (1991) as for as abdominal pain and fever is concerned. The likely reason seems to be mode of presentation. In present study, $(87.15 \%)$ patients presented in emergency department. Mode of presentation in the above studies was mostly elective admissions. There are also some differences in other clinical presentations, when we compare present study to study conducted by Manzoor Ahmad et al ${ }^{10}$ in 1998 and Hakim Ali Abro et al ${ }^{8}$ in 1998. As tuberculosis can present with diverse clinical features mostly are nonspecific symptoms so we can expect these differences. More over in present study most of the patients presented in emergency department with history suggestive of either intestinal obstruction or peritonitis so pain and vomiting are the leading symptoms in present study.

As for investigations were concerned, on $\mathrm{x}$ - ray abdomen, 52 patients $(47.70 \%)$ showed distended bowel loops with air fluid levels and air under diaphragm was present in 14 patients $(12.84 \%)$. By comparing with the literature ${ }^{10}$, distended bowel loops were present in $50 \%$ patients. In present study barium study was conducted in 29 patients. Only 20 patients showed narrowing and mucosal deformities in ileum, jejunum and ascending colon. Two patients showed multiple fistulae between gut. When we compare the results of present study with study conducted by Manzoor Ahmad et $\mathrm{al}^{10}$ in 1998 where barium study was conducted in 6 patients and it was positive in 3 patients showing narrowing and psudopolyps.

Ultrasonography was done in all patients in present study. In 25 patients $(22.96 \%)$, there was ascities with thickened bowel loops in 22 patients $(20.18 \%)$. Mass was present in right lower abdomen in 15 patients (13.76\%). When we compare present study with study conducted by Hakim Ali Abro et al ${ }^{8}$, Ultrasonography was done in all patients while thickened bowel loops were identified in 14 cases and mass was present in 4 cases. As Ultrasonography is operator dependent so difference between the results could be expected.

PCR for intestinal tuberculosis can be regarded as useful test. We used this technique on biopsy specimen during Colonoscopy and also on patients with ascities. PCR was positive in all $25(100 \%)$ patients with ascities. 14 out of 15 patients $(93.33 \%)$ showed positive results on biopsy specimen revealed by Colonoscopy. In literature, PCR is regarded as beneficial test in diagnosing abdominal tuberculosis ${ }^{11,12,13,14}$.

\section{Conclusions:}

Intestinal tuberculosis is a common disease in third decade in developing countries like Pakistan. Females are more affected than males in these areas of the world because of male dominant society and poor nutrition status of females. Poor sanitation, lack of drinking water facilities, lack of health facilities and above all ignorance are the major factors for spread of this disease in the developing countries. Primary tuberculosis is more common than secondary tuberculosis. In our study, majority of patients presented with complications of intestinal tuberculosis. Their socioeconomic status was low. Intestinal tuberculosis may present with a variety of non-specific abdominal symptoms and signs. So the patients presenting with non-specific abdominal complaints that is history of off and on abdominal pain with weight loss, night sweats should be investigated for intestinal tuberculosis. Histopathology and PCR can be considered as gold standard in diagnosing intestinal tuberculosis.

\section{References:}

1. Richard M. Mendelson. The gastrointestinal tract. In: A Global Text Book of Radiology. The Nicer Institue Olso. 1995:965-6.

2. Philip ES Palmer, Maurice M. Reader, Susan D Wall. Gastrointestinal tuberculosis. In: Practical Alimentary Tract Radiology. Mosby year book, Baltimore 1993: 384-85.

3. Homan WP et al. A44 years experience with tuberculosis enteritis Word J. Surgery. 1997; 1(2): 245.

4. A. Cuscheiri. Small intestine and vermiform appendix. A. Cuscheiri, GR Giles, AR Moosa. Essential Surgical Practice $3^{\text {rd }}$ edition. Butterworth-Heimann. 1995-76.

5. Ayyaz M, Rathore MA, Afzal MF, Abdullah MA, Waris M, Chaudhary ZU et al. Changing trends in abdominal tuberculosis. Pan J Surg. 1996; 12(4): 186-8.

6. Sircar S, Taneja VA, Kansura U. Epidemiology and clinical presentation of abdominal tuberculosis retrospective study. J Indian Med Assoc. 1996 Sep; 94(9); 342-4.

7. Aston NO. Abdominal Tuberculosis. World J Surg. 1997 Jun; 21 (9): 492-9.

8. Hakim Ali Abro, Rukhsana, Jamal Arfa and Shabeer Hussain. Abdominal tuberculosis presentation and early diagnosis. Journal of Surgery Pakistan (International) Vol. 3 (2): April-June 1998.

9. Chang-H, Leu-S, Lui-WY. Abdominal tuberculosisretrospective analysis of 121 cases. Chung-Hua-I-HusehTsa-Chih-Taipei. 1991 Jan; 47(1): 24-30.

10. Manzoor Ahmad, Muhammad Azhar Mughal, Muhammad Azam. Varied intestinal tuberculosis An experience at Sundeman Hospital Quetta. JCPSP Vol. 10(7): 246-248.

11. Fakhar Hameed, Muhammad Akram Malik. Abdominal Tuberculosis - Profile of 50 Cases. J Coll Physicians Surg Pak Apr 2000; 10(4): 125-7.

12. Khan IM.. Diagnosis of abdominal Tuberculosis in surgical patients. J Postgrad Med Inst Sep 2004; 18(3): 500-6.

13. Amarapurkar DN; Patel ND; Amarapurkar AD; Agal S; Baigal R; Gupte P. Tissue polymerase chain reaction in diagnosis of intestinal tuberculosis and Crohn's disease. J Assoc Physicians India 2004 Nov; 52:863-7.

14. Martinez Tirado P; Lopez De Hierro Ruiz M; Martinez Garcia R; Martinez Cara JG; Martin Rodriguez MM; Castilla Castellano MM. [Intestinal tuberculosis. A diagnostic challenge] Gastroenterol Hepatol 2003 Jun-Jul; 26(6): 351-4. 